\title{
Developmental coaching: theory and practice
}

\author{
- $\quad$ Abstract \\ Although coaching is often portrayed in the literature and amongst coaches as a \\ developmental enterprise, the concept of developmental coaching is less than clear and \\ open to misinterpretations. This paper introduces a theory specifically developed for \\ coaching practice and fully described in the author's book »Developmental Coaching: \\ Working with the Self «. The theory is based on a new conceptualisation of the self and \\ suggests a developmental framework that implies a certain trajectory in the adult \\ development process. For coaching practice this theory advocates an individual approach to \\ coaching clients of the three different groups and suggests three mechanisms of influencing \\ development.
}

Many coaches nowadays present themselves as developmental coaches rather than skills or performance coaches, but rarely the explanation of this term is provided. The review of literature that uses explicitly the term of developmental coaching (Berman \& Bradt 2006; Hawkins \& Smith 2006, 2010; Cox \& Jackson 2014; Palmer \& McDowall 2007) shows that this concept is poorly defined with some elements overlapping and others contradicting each other. For example, developmental coaching as a genre is described as:

holistic - addresses the whole person rather than only work-related goals, addressing long-standing behaviour problems, used for working through transitions during the lifespan, aiming to increase the broader human capacities of clients, implying a non-directive approach, suitable to use for a better trained external coach rather than for a manager as coach or an internal coach.

It is clear that some contradictions in this mix indicate the lack of a unifying theory behind the approach. However, in spite of conceptual and theoretical weaknesses, the actual practice of developmental coaching as a genre is apparently vast and growing.

On the other hand, there is a multitude of well-known and respected theories in the field of adult development (e.g. Kegan 1982; Torbert 1991; Graves 1970; Cook-Greuter 1999; Wilber 2000) that have prompted development of various applications to coaching. These theories 
suggest that people undergo significant changes in terms of their meaning making, moral reasoning and many other aspects during their lifetime. These changes occur in a logical sequence of stages throughout the life of each individual and influence the way people feel, make meaning and engage with their environment. They argued that development can be influenced by other people who can provide appropriate support and challenge in a timely way if they are able to identify the developmental trajectories of those they aim to help. Interestingly, none of these authors refer to the practical approaches that follow from their theoretical contribution as a form of developmental coaching.

The value of the insight these theories provide for individualised approach to coaching clients is obvious. Practical applications of some theories described, for example, by Berger (2012); Berger and Fitzgerald (2002), Kegan and Lahey (2009), Berger and Atkins (2009) show how useful these theories can be for coaching practice. However, there are also some issues that prevent effective use of them in coaching. The main issue is associated with the need to use complex and labour-intensive instruments of measurement that require not only sophisticated training but also a high level of development of the scorers themselves. Another issue is about intention for precision when these instruments are used. This precision is not justified for coaching for several reasons. For example, there are factors that interfere with the quality of measurement such as verbal fluency and educational and social background (McCauley et al. 2006; Manners \& Durkin 2001). There is also a concern about the prediction of progressive sequence in development. Although several longitudinal studies provide support for sequentuality of stages, they also challenge the theorised irreversibility, for example, of ego development (Adam \& Fitch 1982; Kohlberg 1969 Westenberg \& Gjerde 1999; Manners \& Durkin 2001).

There are two further concerns in applying cognitive-developmental theories in coaching practice (Bachkirova 2014 2011). The first one suggests that developmental stages, instead of being a source of deeper understanding of the client, may become a main focus of attention in coaching creating an illusion that development can happen as the result of high motivation and efforts by the client or the magical skills by the coach. Secondly, even if the above is avoided, there is a limitation of each individual theory being focused on one particular developmental line. However, the actual coaching assignments are more complex and multifaceted. When coaches encounter an individual client, they may need to work with a variety of themes such as interpersonal, cognitive, emotional, etc. This should involve addressing each area of development with an open mind in spite of the indication of a particular stage in some of the others (Bachkirova 2011, 2013). 
To summarise, developmental coaching as a genre is becoming widespread amongst practitioners. However, it suffers from the incompatibility of various conceptualisations of developmental coaching and the lack of a unifying theory behind the approach. On the other hand, there is a solid body of research and theory behind adult development theories, but considerable issues associated with the diagnostic instruments which they entail prevents wider applications of these theories in coaching practice.

\section{A new theory of developmental coaching}

To rectify the issues identified above a new theory of developmental coaching is proposed.

The theory does not claim a discovery of new laws of human nature, rather a new synthesis of ideas that allows integration of many other approaches to facilitating individual development. It draws from the wider fields of knowledge such as psychology, philosophy and neuroscience and shares concepts with the existing practical approaches to coaching.

The theory suggests the importance of understanding the nature of self as changes in the self indicate an opportunity of individual approach implied in developmental coaching. For example, the proposed concepts emphasise a division between the conscious mind and the rest of the organism including unconscious, automatic operations and the body. An analogy of the rider and the elephant are used (Haidt 2006) to illustrate that the role of the conscious mind, as a rider is significantly exaggerated in the functioning of the whole organism.

The theory proposes that there are at least three separate notions of self which helps to explain confusions in the extensive literature about the nature of self. From the phenomenological perspective the self will be seen as an experiential dimension postulating a simple »I« as the most basic pre-reflective sense of self. In a more objective sense the properties and areas of the brain that are associated with the actions of the organism have to be considered. As a second notion it is postulated that there is a neurological network, an executive centre (ego), responsible for the coherent behaviour and normal functioning of the individual in the world. Finally, the self is also seen as a narrative construction, an aspect of human nature (narrator) that explains the view of the self that we consciously and linguistically conceive. Overall on the basis of current findings in various studies a case is made that the three main elements for understanding the self are:

sense of I as a pre-reflective self-consciousness - centre of awareness, ego as an executive centre, self-stories constructed by a narrator (conscious and reflective linguistic function of the $\operatorname{mind}$ /brain) - identity centre. 
It is argued that the executive centre or ego, as a network of mini-selves, is the most important notion for applied purposes. Each mini-self is a combination of brain/mind states and processes that are involved in the organism's engagement with a certain task or more precisely, it is a particular pattern of links between different areas of the brain that become activated or inhibited when the organism is involved in an act. These patterns may involve not only sensory stimuli, but memory, cognition, interpretation of meaning, and so on. Many mini-selves work simultaneously in different circumstances. Therefore, the ego, functioning mainly subconsciously, is responsible for satisfying the organism's needs. Consciousness may not be involved when these needs are unambiguous. However, when there is greater ambiguity, complexity or greater leisure the mini-selves may involve conscious layers of information from memory, perception or beliefs (Gazzaniga 1985; Claxton 1994).

It is important to clarify that although these notions of self are called »centres« for uniformity, neither of them implies a reality of a specific place in the mind/brain, which could justify a vision of the self as a little operator in charge of the organism. Only the first of these centres may feel like a centre from the phenomenological perspective, but two other notions both imply multiplicity of mini-selves or self-stories.

\section{Three mechanisms of developmental coaching}

The aim of developmental coaching is to facilitate »organic change« - a change that is initiated in the executive centre, implying that a new mini-self is getting ready to be formed to satisfy a need that is important to the whole organism. That is why there is a natural energy behind it. In order for a new mini-self to emerge most elements of it should be in place: channels to receive information from inside and outside the organism, necessary functional skills and motor-schemas to be activated, including links in the brain that can contribute to preparing this mini-self to go live. However, the organic change can be blocked and coaching may become a viable option. These blockages suggest that something is missing in the working cycle of the mini-self. It could be at any section of this cycle: input section, action section or communication between them. Therefore there could be at least three types of blockages or obstacles to organic change which could be addressed by means of developmental coaching:

low quality of information at the input point, interruption from the narrator at the process of communication, no obvious behaviour routes exist at the action point. 
It is postulated that attention to these potential obstacles in developmental coaching will enhance client's engagement with the change they are aiming at. Consequently it is proposed that the main mechanisms that allow an organic change to take place are:

Improving the quality of perception

Working with the multiplicity of self-stories

Working with the elephant (unconscious, automatic parts of mind/brain and body).

In order to improve the quality of perception both internally and externally coaches traditionally aim at development of active listening skills, observation skills, attention to body language, etc. In coaching two main issues which interfere with a quality of perception: conditioning and self-deception should be addressed. Conditioning comes with getting »second-hand knowledge« and is useful to some extent. But we are often conditioned by the culture of organisations, by circles of friends, by society as a whole in ways that prevent change and development. The second obstacle to perception is self-deception. Whilst during conditioning the filters to perception of reality are polished by influential others, in selfdeception this job is done internally. Working with the holes in clients' perception is a task of developmental coaches.

The next mechanism of developmental coaching is working with multiplicity of self-stories. It appears that the narrator, being a linguistic function in the rider, has developed in evolution together with our ability to use language. The narrator puts together conscious stories or theories of self that we think we are. Some of these stories may be less then helpful in the process of change. Coaches can assist clients in accepting the fact of multiplicity, matching a self-story with a real mini-self and working on the synthesis of self-stories.

The third mechanism of change working with the elephant (the emotional unconscious mind and the body) is about better interaction between the rider and the elephant in the process of organic change. One way of addressing this is promotion of soft thinking (Claxton 1999, p. 146) in addition to traditional hard reasoning which implies the inhibition of other parts of the mind. Soft thinking instead implies a soft focus, »looking at« rather than »looking for« (Claxton 1999; Claxton \& Lucas 2007) without forcing out new, unstable and fragile ideas that come from the unconscious. Another way of working with the elephant is better communication with the emotional body, improving two-way traffic between the rider and elephant (Bachkirova 2011). 


\section{Coaching according to developmental themes}

Although it was proposed that the above mechanisms are fundamental for developmental coaching they must be applied in a different way for different people at different stages of life and for different problems that need to be tackled. For coaching purposes it is particularly important important to know how clients engage in action. Therefore, developmental coaching suggests an individual approach to clients according to their stage of ego development - a centre that is responsible for engagement in action.

The ego could be developed to various degrees, from unformed to fully formed. When the ego is fully developed the mind/brain can act or refrain from action if necessary in a way that reasonably satisfies the organism as a whole with all the multiplicity of its needs and tasks. With the unformed ego there are needs that remain unsatisfied and tasks unfulfilled. They actually need more help or guidance from others. The sign of a fully formed ego is the capacity of the whole organism to take ownership of the past, withstand anxiety about what the future holds and build relationships with others without losing the sense of who they are. Their choices may be constructive or destructive, but they are made according to their own criteria that can be rationally explained. At the same time this stage of the ego is associated with other developmental challenges. The sense of control and self-ownership may lead to an overestimation of what is possible and realistic for the organism, which may result in a lack of attention to and even abuse of the body when working to achieve some specific targets. The third category, a reformed ego, represents capacities of the ego that go beyond those of the formed ego. There is a much more harmonious relationship between the elephant and the rider, manifested in the ability of the organism to tolerate the ambiguity of some needs and tasks, thus minimising energy wasted on conflicts between the various mini-selves. Table 1 presents three stages of ego development. It included characteristics from various theories. However, the number of stages is reduced to three for simplicity and because various statistical data suggest that these are the most characteristic for the majority of adults (Beck \& Cowan 1996; Wilber 2000; Torbert 1991). It is so more likely that they will represent a clientele of coaches. The stages are described in four major aspects of the individual: cognitive style, interpersonal style, conscious preoccupations and character development with a fifth aspect proposed in the theory of developmental coaching (Bachkirova 2011).

Table 1: A cumulative description of the three stages in adult development with addition from Bachkirova (2011)

\begin{tabular}{|l|l|l|l|}
\hline Stages & Unformed ego & Formed ego & Reformed ego \\
\hline
\end{tabular}




\begin{tabular}{|c|c|c|c|}
\hline $\begin{array}{l}\text { Cognitive style } \\
\text { (based mostly on } \\
\text { Kegan 1982) }\end{array}$ & $\begin{array}{l}\text { Socialised mind } \\
\text { Ability for abstract } \\
\text { thinking and self- } \\
\text { reflection }\end{array}$ & $\begin{array}{l}\text { Self-authoring mind } \\
\text { Can see multiplicity and } \\
\text { patterns; critical and } \\
\text { analytical }\end{array}$ & $\begin{array}{l}\text { Self-transforming mind } \\
\text { Systems view; tolerance of } \\
\text { ambiguity; change from } \\
\text { linear logic to holistic } \\
\text { understanding }\end{array}$ \\
\hline $\begin{array}{l}\text { Interpersonal style } \\
\text { (Loevinger 1987; } \\
\text { Cook-Greuter 1999) }\end{array}$ & $\begin{array}{l}\text { Dependent } \\
\text { Conformist/self- } \\
\text { conscious } \\
\text { Need for belonging; } \\
\text { socially expected } \\
\text { behaviour in } \\
\text { relationships; } \\
\text { peacemakers/keepers }\end{array}$ & $\begin{array}{l}\text { Independent } \\
\text { Conscientious/ } \\
\text { individualist } \\
\text { Separate but responsible for } \\
\text { their own choices; } \\
\text { communication and } \\
\text { individual differences are } \\
\text { valued }\end{array}$ & $\begin{array}{l}\text { Inter-independent } \\
\text { Autonomous/ } \\
\text { Integrated } \\
\text { Take responsibility for } \\
\text { relationship; respect } \\
\text { autonomy of others; } \\
\text { tolerance of conflicts; non- } \\
\text { hostile humour }\end{array}$ \\
\hline $\begin{array}{l}\text { Conscious } \\
\text { preoccupations } \\
\text { (Graves 1970) }\end{array}$ & $\begin{array}{l}\text { Multiplistic } \\
\text { Social acceptance, } \\
\text { reputation, moral } \\
\text { »shoulds and oughts» }\end{array}$ & $\begin{array}{l}\text { Relativistic/ } \\
\text { Individualistic } \\
\text { Achievement of personal } \\
\text { goals according to inner } \\
\text { standards. }\end{array}$ & $\begin{array}{l}\text { Systemic/integrated } \\
\text { Individuality; self-fulfilment; } \\
\text { immediate present; } \\
\text { understanding conflicting } \\
\text { needs }\end{array}$ \\
\hline $\begin{array}{l}\text { Character } \\
\text { development } \\
\text { (Loevinger 1987; } \\
\text { Cook-Greuter 1999; } \\
\text { Kolhberg 1969) }\end{array}$ & $\begin{array}{l}\text { Rule-bound } \\
\text { »Inappropriate« feelings } \\
\text { are denied or repressed. } \\
\text { Rules of important others } \\
\text { are internalised and } \\
\text { obeyed. }\end{array}$ & $\begin{array}{l}\text { Conscientious } \\
\text { Self-reliant, conscientious; } \\
\text { follow self-evaluated rules; } \\
\text { judge themselves and } \\
\text { critical of others }\end{array}$ & $\begin{array}{l}\text { Self-regulated } \\
\text { Behaviour is an expression } \\
\text { of own moral principles. } \\
\text { Concerned with conflicting } \\
\text { roles, duties, value } \\
\text { systems. }\end{array}$ \\
\hline $\begin{array}{l}\text { Engagement in action } \\
\text { (Bachkirova 2011) }\end{array}$ & $\begin{array}{l}\text { Unformed ego } \\
\text { Reduced sense of } \\
\text { control over themselves } \\
\text { and environment. Higher } \\
\text { dependency on others } \\
\text { for action. }\end{array}$ & $\begin{array}{l}\text { Formed ego } \\
\text { Capacity to take ownership } \\
\text { of the past and act } \\
\text { independently. »Mind over } \\
\text { body« control of action. }\end{array}$ & $\begin{array}{l}\text { Reformed ego } \\
\text { Harmony between mind and } \\
\text { body in action. Appreciation } \\
\text { of complexity in the } \\
\text { relationship between self } \\
\text { and environment. }\end{array}$ \\
\hline
\end{tabular}

The main difference that is proposed with the fifth aspect is that it does not need any use of the instruments of measurement. The concerns and the goals that clients bring to coaching can show a pattern that is developmental. These themes are not only about goals - they are about the challenges that people face in life, what they find difficult, what their life circumstances demand from them. The pattern in the themes (table 2) would indicate the stage of the ego in each client and will help to shape an individual approach to coaching.

Table 2: Three groups of developmental themes (Bachkirova 2013)

\begin{tabular}{|l|l|l|}
\hline Unformed ego & Formed ego & Reformed ego \\
\hline Decision-making in difficult & Coping with high amount of self- & Dissatisfaction with life in spite \\
situations with a number of & of achievements \\
stake-holders & Achievement of recognition, & Internal conflict \\
\hline
\end{tabular}




\begin{tabular}{|l|l|l|}
\hline Taking higher level of & promotion, etc. & Not »fitting in « \\
responsibility than they feel they & Interpersonal conflicts & Search for meaning \\
can cope with & Drive for success and underlying & Overcoming life crisis \\
Work-life balance connected to & fear of failure & Initiating a significant change \\
inability to say »no» & Problem solving & Dealing with personal illusions \\
Performance anxiety & Learning to delegate & Staying true to themselves in a \\
Issues of self-esteem & Stress management & complex situation \\
& & \\
\hline
\end{tabular}

This theory also proposes a fourth stage of ego with a soul. This stage can also be identified by the themes that the client might wish to explore, e.g.:

intention for spiritual development,

lack of progress in a chosen path,

making sense of a mystical experience,

coming to terms with mortality of the organism,

realisation of incompleteness of work for a mission,

overcoming spiritual illusions.

However this stage is treated differently from the other three. It is more complex because it involves at least three potentially overlapping groups of individuals:

1. those who demonstrate unusual capacities that may indicate a stage, reached by a few;

2. those who have had special (spiritual) experiences which may happen to many people;

3. those who have deep interest in the spiritual, an inclination that could be shared by anyone.

Only the first group could be considered as a fourth stage. The clients from the other two groups may bring for coaching a theme of this stage, but most likely they would be identified as gravitated to one of the previous three stages.

The developmental coach would approach a new assignment initially in the same way as any other coach: identifying the clients' needs, exploring their situation fully and clarifying the goals. However, she would gradually uncover a sense of the state of the client's ego from taking into account the issues they both identified, the challenges the client faces and the difficulties he/she experiences. The task of the coach is to engage with whatever issue/goal is presented, but noticing at the same time a pattern in these: a developmental theme. The job to do between the sessions is to explore these patterns and consider relevant coaching strategies 
through reflection on the previous sessions, preparation for the coming sessions and discussion of these cases in supervision.

In terms of selecting specific interventions, coaches may choose to use any appropriate tools and methods that they are familiar with. There are traditional coaching approaches particularly useful for some specific developmental themes. For example, Cognitivebehavioural coaching and Transactional Analysis have good methods suitable for working with unformed ego. The Existential approach on the other hand fits well when working with reformed ego. In addition to these approaches the developmental coach would also be considering the three main mechanisms: working with perception, the elephant and the multiplicity of self-models.

\section{Conclusion}

This theory and approach are one possible way of seeing the role of coaching on a wider scale of the psychological evolution and at the same time as an intimate one-to-one interaction with a focus on a concrete theme important for a client. As any theory, this is only one particular map to a vast territory of individual change and ways of facilitating it, which I hope could be useful for coaches and could contribute to the body of knowledge about influencing individual development.

\section{- $\quad$ References}

Adams, G., \& Fitch, S. (1982). Ego stage and identity status development: A cross sequential analysis. Journal of Personality and Social Psychology 43, 574-583.

Bachkirova, T. (2011). Developmental Coaching: Working with the self. Maidenhead: Open University Press.

Bachkirova, T. (2013). Developmental coaching: Developing the Self. In J. Passmore, D. Peterson \& T. Freire (eds.), The Wiley-Blackwell Handbook of the Psychology of Coaching and Mentoring (pp. 135-154).

Chichester: John Wiley.

Bachkirova, T. (2014). Psychological Development in Adulthood and Coaching. In E. Cox, T. Bachkirova \& D. Clutterbuck (eds.), The Complete Handbook of Coaching (2nd ed.) (pp. 131-144). London: Sage.

Bachkirova, T., \& Cox, E. (2007). A Cognitive Developmental Approach for Coach Development. In S. Palmer \& A. Whybrow (eds.), Handbook of Coaching Psychology: A Guide for Practitioners (pp. 325-350). London: Routledge.

Beck, D., \& Cowan, C. (1996). Spiral Dynamics. Oxford: Blackwell.

Berger, J. (2012). Changing on the Job: Developing Leaders for a Complex World. Stanford: Stanford Business Books.

Berger, J., \& Atkins, P. (2009). Mapping complexity of mind: using the subject-object interview in coaching, Coaching: An International Journal of Theory, Research and Practice 2 (1), 23-36.

Berger, J., \& Fitzgerald, C. (2002). Leadership and Complexity of Mind: The Role of Executive Coaching. In C. Fitzgerald \& J. Berger (eds.), Executive Coaching: Practices \& Perspectives (pp. 27-58). Palo Alto: DaviesBlack Publishing. 
Berman, W., \& Bradt, G. (2006). Executive Coaching and Consulting: «Different Strokes for Different Folks«. Professional Psychology: Research and Practice 37 (3), 244-253.

Claxton, G. (1994). Noises from the Darkroom. London: Aquarian.

Claxton, G. (1999). Wise-Up: The Challenge of Lifelong Learning. London: Bloomsbury.

Claxton, G., \& Lucas, B. (2007). The Creative Thinking Plan: How to generate ideas and solve problems in your work and life. London: BBC Books.

Cook-Greuter, S. (1999). Postautonomous ego development: its nature and measurement. Doctoral dissertation. Cambridge, Harvard Graduate School of Education.

Cox, E., \& Jackson, P. (2014) (2 ed). Developmental Coaching. In E. Cox, T. Bachkirova \& D. Clutterbuck (eds.), The Complete Handbook of Coaching (pp 215-227). London: Sage.

Gazzaniga, M. (1985). The Social Brain. New York: Basic Books.

Graves, C. (1970). Levels of Existence: An Open system Theory of Values. Journal of Humanistic Psychology, $10(2), 131-155$.

Haidt, J. (2006). The Happiness Hypothesis. London: Arrow Books.

Hawkins, P., \& Smith, N. (2006). Coaching, Mentoring and Organizational Consultancy: Supervision and Development. Maidenhead: Open University Press.

Hawkins, P., \& Smith, N. (2010). Transformational Coaching. In E. Cox, T. Bachkirova \& D. Clutterbuck (eds.), The Complete Handbook of Coaching (pp. 231-244). London: Sage..

Kegan, R. (1982). The Evolving Self: Problem and Process in Human Development. London: Harvard University Press.

Kegan, R. \& Lahey, L.(2009). Immunity to Change: How to overcome it and unlock the potential in yourself and your organisation. Boston: Harvard Business Press.

Kohlberg, L. (1969). Stages in the development of moral thought and action. New York: Holt, Reinhart and Winston.

Loevinger, J. (1987). Paradigms of Personality. New York: Freeman.

Manners, J., \& Durkin, K. (2001). A Critical Review of the Validity of Ego Development Theory and Its Measurement. Journal of Personality Assessment 77 (3), 541-567.

McCauley, C., Drath, W., Palus, P., \& Baker, B. (2006). The use of constractive-developmental theory to advance the understanding of leadership. The Leadership Quarterly 17, 634-653.

Palmer, S., \& McDowall, A. (eds.) (2007). Developmental Coaching. London: Routledge.

Torbert, W. (1991). The Power of Balance. Newbury Park: Sage.

Westenberg, P., \& Gjede, P. (1999). Ego development during the transition from adolescence to young adulthood: A 9-year longitudinal study. Journal of Research in Personality 33, 233-252.

Wilber, K. (2000). Integral Psychology. London: Shambala. 